\title{
Obtaining anthocyanin-rich extracts from frozen açai (Euterpe oleracea Mart.) pulp using pressurized liquid extraction
}

\author{
Sylvia Carolina ALCÁZAR-ALAY ${ }^{1}$, Fiorella Patricia CARDENAS-TORO ${ }^{1}$, Juan Felipe OSORIO-TOBÓN', \\ Gerardo Fernandez BARBERO², María Angela de Almeida MEIRELES ${ }^{1 \star}$
}

\begin{abstract}
Açai is considered a functional food, and in addition to being a source of energy and fiber, it is a valuable source of bioactive compounds such as anthocyanins, minerals and fatty acids. In the present work, antioxidant-rich extracts from açai pulp were obtained using pressurized liquid extraction (PLE). The effects of the independent variables, including solvent type (pure ethanol and ethanol/water $(50: 50 \mathrm{v} / \mathrm{v}))$, citric acid $(0$ and $0.3 \%, \mathrm{w} / \mathrm{w})$, pressure $(20$ and $80 \mathrm{bar})$ and temperature $\left(30\right.$ and $\left.60{ }^{\circ} \mathrm{C}\right)$ were evaluated using a full factorial design. The extraction was affected primarily by the solvent type and the citric acid percentage. The results indicate that the maximum overall yield $\left(\mathrm{X}_{0}\right)$ was $64 \pm 9(\%$, d.b.) when the process was performed using ethanol $(99.5 \%)$ and citric acid $(0.3 \% \mathrm{w} / \mathrm{w})$. The maximum total anthocyanin content and anthocyanin recovered from the raw material were $7 \pm 1$ (mg anthocyanin/g extract, d.b.) and $11 \pm 2$ (\%, d.b.), respectively.
\end{abstract}

Keywords: flavonoids; phenolic compounds; antioxidant; biocompounds recovery; clean technology.

Practical Application: Anthocyanin extraction for food and pharmaceutical industry.

\section{Introduction}

Açai (Euterpe oleracea Mart.) is a palm tree commonly found in northern South America, mainly within the Brazilian Amazon (Oliveira \& Santos, 2011). A wide variety of marketable products are produced from this plant, the spherical fruits being the most important edible products (Del Pozo-Insfran et al., 2004). Recently, açai has attracted worldwide interest due to its exotic flavor and its bioactive properties, such as antioxidant capacity and anti-inflammatory activity (Kang et al., 2011; Pacheco-Palencia et al., 2007; Schauss et al., 2006b). The açai pulp has a high content of phenolic compounds such as anthocyanins, proanthocyanidins, other flavonoids and lignans (Schauss et al., 2006a). Anthocyanins contribute to preventing some degenerative diseases, and their effects on human health. Have been mainly attributed to their antioxidant ability to reduce the free radicals and prevent cardiovascular problems and other diseases (Kruger et al., 2014; Spada et al., 2009). The anthocyanins are a group of flavonoid compounds that are responsible for the red, violet and blue color of fruits and vegetables such as strawberries, grapes and cranberries, among others (Newsome et al., 2014). Therefore, anthocyanins are considered a possible substitute for synthetic dyes used in foods due to their attractive color and high solubility in aqueous media. Additionally, anthocyanins are considered to be nontoxic and safe additives (Pina et al., 2012). However, there are some limitations for commercial uses of anthocyanins due to the availability of feedstocks (quantity and quality), difficulty in purifying the extracts, the high cost of raw materials and low stability during processing and storage (Del Pozo-Insfran et al., 2004; Liazid et al., 2014).

The growing interest in the recovery of biocompounds such anthocyanins from vegetal matrices with possible applications in the food, pharmaceutical and cosmetic industries represents an important opportunity (Machado et al., 2014). Anthocyanins are generally extracted using methanol, ethanol, acetone, water or a mixture of these solvents (Welch et al., 2008). Anthocyanins are relatively unstable pigments, and temperature is the main factor that triggers the degradation of the anthocyanins. Other factors, such as their chemical structure, $\mathrm{pH}$, presence of light, ions, enzymes or oxygen, can trigger their degradation (Liazid et al., 2014; Sui et al., 2014). However, the color stability of the anthocyanins is increased under acid presence due to the antibrowning effects (Altunkaya \& Gökmen, 2009). In this context, to improve the extraction yield, the addition of small quantities of acid (e.g., hydrochloric, formic and citric acid) can be considered to enhance the extraction efficiency (Adjé et al., 2010).

PLE is an environmental friendly extraction technique that allows overcoming the inconveniences of traditional techniques, whereas extracts with high quality and purity are obtained. The PLE process has become a feasible alternative for recovering bioactive compounds from vegetal feedstock (Liazid et al., 2014; Liu et al., 2014; Machado et al., 2014). PLE uses elevated temperatures (30-200 ${ }^{\circ} \mathrm{C}$ ) and moderate to high pressures $(35-200 \mathrm{bar}$ ) to facilitate and enhance the extraction process. PLE is also referred to elsewhere as pressurized fluid extraction (PFE), accelerated 
solvent extraction (ASE), pressurized solvent extract ion (PSE) or enhanced solvent extraction (ESE). As the extraction process is performed using high pressures, the solvent remains in a liquid state, even when the temperatures are above the boiling point of the solvent (Richter et al., 1996). Thus, PLE can operate at high temperatures to increase the solubility and desorption of the target compounds from the matrix (Nieto et al., 2010). In the PLE process, the pressure and temperature can be adjusted to improve the selectivity of the extraction solvent over a particular group of compounds (Carabias-Martínez et al., 2005; Liu et al., 2014). In the PLE process, solvents are generally recognized as safe (GRAS), such as water, ethanol or their mixtures, and are commonly used for phenolic and anthocyanin extraction (Mane et al., 2015; Rodrigues et al., 2015).

In this context, the objective of this study was to evaluate PLE for obtaining anthocyanins from frozen açai pulp. The process parameters such as temperature, pressure, solvent and citric acid were evaluated to obtain anthocyanin-rich extracts. Pure ethanol and ethanol/water (50:50 v/v) were used as solvents because they are GRAS solvents. To evaluate the citric acid effects on the anthocyanin extraction process, citric acid was added into the extraction solvent.

\section{Materials and methods}

\subsection{Chemicals}

Ethanol (PubChem CID: 702) (Dinâmica, Diadema, Brazil) and citric acid (PubChem CID: 311) (Synth, Diadema, Brazil) were used. Ultra-pure water was obtained from a Milli-Q water purifier system (Millipore, Bedford, USA). The chemicals and solvents used in the anthocyanin analysis were methanol (Merck, Darmstadt, Germany) and formic acid (Panreac, Barcelona, Spain) at high-performance liquid chromatography (HPLC) grade. Cyanidin chloride (Sigma-Aldrich Chemical Co., St. Louis, USA) was used as the anthocyanin standard. Chemical compounds studied in this article: Cyanidin-3-O-glucoside (PubChem CID: 12303203); Cyanidin-3-O-rutinoside (PubChem CID: 29232); Peonidin-3-O-glucoside (PubChem CID: 14311151); Cyanidin Chloride (PubChem CID: 68247).

\subsection{Raw material}

Frozen açai pulp (De Marchi, São Paulo, Brazil) was obtained from a local market located in Campinas, Brazil. The raw material was kept at $-18^{\circ} \mathrm{C}$ before use. The moisture content was determined by lyophilization (LIOBRAS, São Carlos, Brazil). The moisture percentage was calculated by the weight difference before and after lyophilization. The dry matter was characterized according to the anthocyanin content using the ultra-high performance liquid chromatography (UHPLC) method.

\subsection{Pressurized liquid extraction (PLE) process}

PLE was performed with homemade equipment as shown in Figure 1. Frozen açai pulp $(5.5 \mathrm{~g})$ was placed inside the extraction cell $\left(5 \mathrm{~cm}^{3}\right)$. The extraction vessel was heated by a heating jacket. The extraction cell assembly containing the raw material was heated for 3 minutes, filled with ethanol and pressurized using an HPLC pump (Thermoseparation Products, California, USA). After reaching the desired pressure, the extraction cell was maintained at the desired temperature for a static period of $5 \mathrm{~min}$. Then, the block and back-pressure valves were opened and carefully adjusted to maintain the system pressure. The dynamic extraction time was $11 \mathrm{~min}$, and the solvent-to-feed ratio (S/F ratio) was 8.5. After the PLE process, the extract was rapidly cooled and protected from light to prevent the degradation of compounds. After extraction, an aliquot $(2 \mathrm{~mL})$ of the extracts was filtered through a $0.22-\mu \mathrm{m}$ nylon syringe filter (Membrane Solutions, Dallas, USA) prior to chromatographic analysis.

\subsection{Determination of overall yield $\left(X_{0}\right)$}

The overall yield $\left(\mathrm{X}_{0}\right)$ was expressed using a dry basis with the Equation 1. $\mathrm{X}_{0}$ was calculated as the ratio of the total mass of the extract $\left(\mathrm{m}_{\text {extract }}\right)$ and the initial mass of the extraction sample $\left(\mathrm{m}_{\text {sample }}\right)$ using a dry basis.

$X_{0}(\%)=\frac{m_{\text {extract }}}{m_{\text {sample }}} \times 100$

\subsection{Anthocyanin analysis}

Sample preparation

The extracts from the açai samples (raw material) were obtained with an ultrasound-assisted extraction technique. Ultrasonic irradiation was carried out using a UP200S sonifier (200 W, $24 \mathrm{kHz}$ ) (Hielscher Ultrasonics, Teltow, Germany), with the sample immersed in a water bath coupled to a temperature

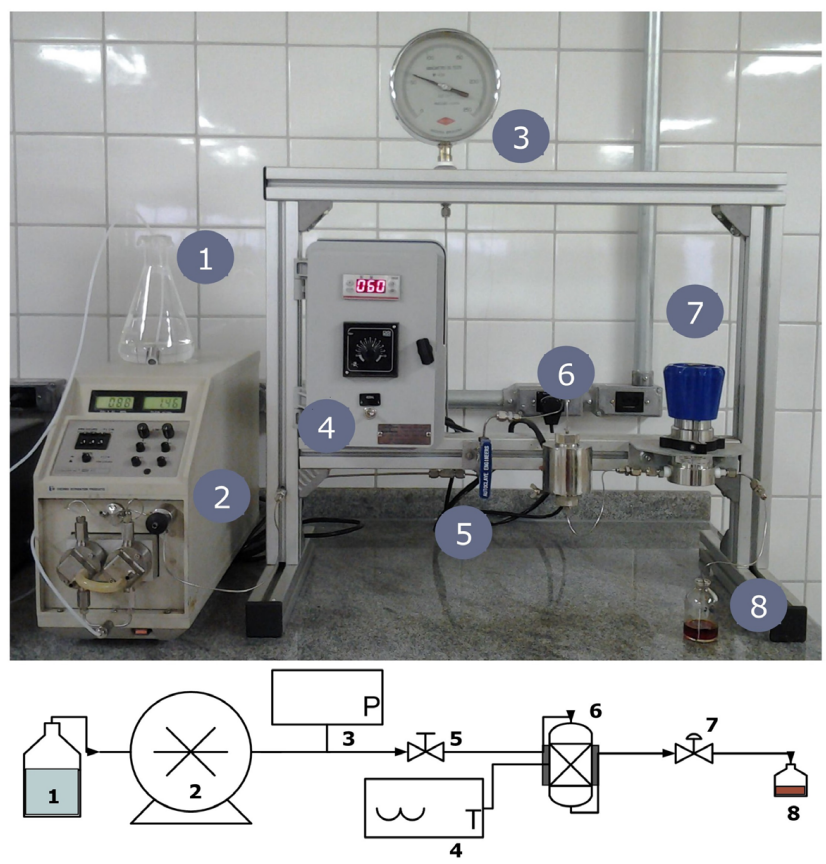

Figure 1. Schematic diagram of the PLE experimental apparatus. (1) solvent reservoir; (2) HPLC pump; (3) manometer; (4) temperature controller; (5) blocking valve; (6) extractor column; (7) back pressure valve; (8) sampling bottle. 
controller (Frigiterm-10, J.P. Selecta, S.A., Barcelona, Spain). The following extraction parameters were used to extract the anthocyanins: extraction solvent: methanol:water ( $\mathrm{pH} 2)(50: 50)$; temperature: $30^{\circ} \mathrm{C}$; output amplitude of the nominal amplitude of the transducer: $100 \%(200 \mathrm{~W})$; duty cycle: $0.5 \mathrm{~s}$; solvent volume: $25 \mathrm{~mL}$; extraction time: 10 minutes; amount of sample: $0.5 \mathrm{~g}$. The extracts were filtered through a $0.22-\mu \mathrm{m}$ nylon syringe filter (Membrane Solutions, Dallas, USA) prior to chromatographic analysis.

\section{Identification of anthocyanins}

The anthocyanins were identified by ultra-performance liquid chromatography (UPLC) coupled to quadrupole-time-of-flight mass spectrometry (Q-ToF-MS) (Waters Corp., Milford, USA). The injection volume was set to $3 \mu \mathrm{l}$. The chromatographic separation was performed on a reverse-phase $\mathrm{C} 18$ analytical column (Waters Corp., Milford, USA) of $2.1 \mathrm{~mm} \times 100 \mathrm{~mm}$ and $1.7-\mu \mathrm{m}$ particle size. For the identification of anthocyanins, water (2\% formic acid) as solvent $\mathrm{A}$ and methanol as solvent $\mathrm{B}$ were the mobile phases at a flow rate of $0.4 \mathrm{~mL} \mathrm{~min}{ }^{-1}$. The gradient employed was as follows: 0 min, $15 \% \mathrm{~B} ; 3.30 \mathrm{~min}, 20 \% \mathrm{~B} ; 3.86 \mathrm{~min}, 30 \% \mathrm{~B}$; $5.05 \mathrm{~min}, 40 \%$ B; $5.35 \mathrm{~min}, 55 \% \mathrm{~B} ; 5.64 \mathrm{~min}, 60 \% \mathrm{~B}, 5.94 \mathrm{~min}$, $95 \% \mathrm{~B} ; 7.50 \mathrm{~min}, 95 \% \mathrm{~B}$. The total run time was $12 \mathrm{~min}$, including $4 \mathrm{~min}$ for re-equilibration. The determination of the analytes was carried out using an electrospray ion source operating in positive ionization mode under the following conditions: desolvation gas flow $=700 \mathrm{~L} \mathrm{~h}^{-1}$, desolvation temperature $=500^{\circ} \mathrm{C}$, cone gas flow $=10 \mathrm{~L} \mathrm{~h}^{-1}$, source temperature $=150^{\circ} \mathrm{C}$, capillary voltage $=700 \mathrm{~V}$, cone voltage $=20 \mathrm{~V}$ and trap collision energy $=4 \mathrm{eV}$. Full-scan mode was used $(\mathrm{m} / \mathrm{z}=100-1200)$. The anthocyanins that were identified in the extracts of açai were cyanidin-3-O-glucoside (C3Gl), cyanidin-3-O-rutinoside (C3R), peonidin-3-O-glucoside (Peo3Gl) and peonidin-3-O-rutinoside (Peo3R). The molecular ions for these anthocyanins presented the following $\mathrm{m} / \mathrm{z}$ ratios: cyanidin-3-O-glucoside, 449; cyanidin-3-O-rutinoside, 595; peonidin-3-O-glucoside, 463; peonidin-3-O-rutinoside, 609.

\section{Separation and quantification of anthocyanins}

The separation and quantification of anthocyanins was performed on an elite UHPLC LaChrom Ultra system (Hitachi, Tokyo, Japan) consisting of an L-2200U autosampler, an L2300 column oven, an L-2160U pump and an L-2420U UV-Vis detector. The column oven was adjusted to $50^{\circ} \mathrm{C}$ for the chromatography. The UV-Vis detector was set at $520 \mathrm{~nm}$ for the analysis. The anthocyanins were analyzed on a HaloTM C18 Hitachi LaChrom column $(100 \times 3 \mathrm{~mm}$ I.D., particle size $2.7 \mu \mathrm{m})$. A gradient method, using acidified water (5\% formic acid, solvent A) and methanol (solvent B) and working at a flow rate of $1.0 \mathrm{~mL} \mathrm{~min}^{-1}$, was employed for the chromatographic separation. The gradient employed was as follows: $0 \mathrm{~min}, 15 \% \mathrm{~B}$; $1.50 \mathrm{~min}, 20 \% \mathrm{~B} ; 3.30 \mathrm{~min}, 30 \% \mathrm{~B} ; 4.80 \mathrm{~min}, 40 \% \mathrm{~B} ; 5.40 \mathrm{~min}$, $55 \%$ B; $5.90 \mathrm{~min}, 60 \%$ B; $6.60 \mathrm{~min}, 95 \%$ B; $9.30 \mathrm{~min}, 95 \% \mathrm{~B}$; $10 \mathrm{~min}, 15 \% \mathrm{~B}$.

\section{UHPLC calibration}

The UHPLC method was used to obtain a calibration curve for cyanidin chloride $(y=300568.88 x-28462.43)$, which is the anthocyanidin standard that is commercially available for cyanidin anthocyanins. The regression equation and correlation coefficient $\left(R_{2}=0.9999\right)$ were calculated using Microsoft Office Excel 2010. The limits of detection $\left(0.198 \mathrm{mg} \mathrm{L}^{-1}\right)$ and quantification $\left(0.662 \mathrm{mg} \mathrm{L}^{-1}\right)$ were also calculated using Microsoft Office Excel 2010. The four anthocyanins present in açai (cyanidin-3-O-glucoside, cyanidin-3-O-rutinoside, peonidin-3-O-glucoside and peonidin-3-O-rutinoside) were quantified using the calibration curve for cyanidin chloride, taking into account the molecular weight of the anthocyanins analyzed. All analyses were carried out in duplicate.

\subsection{Determination of anthocyanin yield (AY)}

Anthocyanin yield (AY) expressed using a dry basis was calculated with Equation 2. AY was calculated by multiplying the value of $\mathrm{X}_{0}$ by the total anthocyanins in the extract

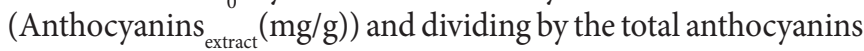
in original sample for extraction (Anthocyanins sample $_{\text {eng }}(\mathrm{mg} / \mathrm{g})$ ).

$A Y(\%)=\frac{X_{0}(\%) \times \text { Anthocyanins }_{\text {extract }}(\mathrm{mg} / \mathrm{g})}{\text { Anthocyanins }}$

\subsection{Statistical analysis}

A full factorial design was used to determine the effects of the extraction parameters, including temperature $\left(30\right.$ and $\left.60^{\circ} \mathrm{C}\right)$, pressure (20 and $80 \mathrm{bar}$ ), solvent type (pure ethanol and ethanol/water $(50: 50 \mathrm{v} / \mathrm{v}))$ and the addition of citric acid $(0$ and $0.3 \% \mathrm{w} / \mathrm{w})$. The experiments were performed in duplicate. Minitab ${ }^{\circledR}$ 16 software was used to analyze the effects of the extraction conditions (temperature, pressure, solvent and percentage of citric acid) on the overall yield $\left(\mathrm{X}_{0}\right)$, total anthocyanin content (TA) and anthocyanin yield (AY) with a confidence interval of $95 \%\left(\mathrm{p}_{\text {value }} \leq 0.05\right)$.

\section{Results and discussion}

\subsection{Raw material characterization}

The moisture content (wet basis) of the frozen açai pulp was $89 \% \pm 2 \%$. This result agrees with the result obtained by Oliveira \& Santos (2011) in a similar sample ( $89 \% \pm 1 \%$ of moisture). That journal article also determined other components on a wet basis, including ash $(0.40 \% \pm 0.03 \%)$, protein $(3.0 \% \pm 0.1 \%)$ lipids $(6.0 \% \pm 0.1 \%)$, total sugar $(2.0 \% \pm 0.7 \%)$, fibers $(4.0 \% \pm 0.1 \%)$ and minor components like calcium and iron. Table 1 lists the anthocyanin content of frozen açai pulp expressed on a dry basis.

According to the quality standard, the açai pulp products are derived from the edible fraction of the açai fruit after recovery of the pulp through appropriate technological processes (Oliveira \& Santos, 2011). The açai pulp is classified according to the amount of total solids. There are three types: thick $(\mathrm{A})$ which has $14 \%$ dry matter and a very dense appearance; average (B) which has $11 \%$ to $14 \%$ dry matter and a dense appearance 
and fine $(\mathrm{C})$ which contains $8 \%$ to $11 \%$ dry matter and a thin appearance (Brasil, 2000). According to the amount of total solids, the raw material used in this study can be classified as type C. For the PLE process, in order to preserve the integrity of the target biocompounds, the frozen açai pulp was not dehydrated.

\subsection{PLE anthocyanin-rich extracts}

Table 2 lists the experimental conditions and the overall yield, the anthocyanin yields, and total anthocyanin content obtained by PLE.

\section{Overall yield $\left(X_{0}\right)$ of $P L E$}

In the temperature, pressure, solvent and citric acid ranges studied, only the combination of solvent and citric acid effects $\left(p_{\text {value }}<0.03\right)$ had a significant impact on the extraction yield. The overall yield varied from $14.5 \%$ d.b. to $63.5 \%$ d.b. The results show that the extraction yield has an increment directly proportional to the increment in concentration of ethanol and

Table 1. Anthocyanin composition in frozen açai pulp (on a dry basis).

\begin{tabular}{cc}
\hline & $\begin{array}{c}\text { Anthocyanin content } \\
(\mathrm{mg} / \mathrm{g})\end{array}$ \\
\hline C3Gl & $0.60 \pm 0.01$ \\
C3R & $10.0 \pm 0.3$ \\
Peo3Gl & $0.30 \pm 0.01$ \\
Peo3R & $0.60 \pm 0.01$ \\
Total Anthocyanins & $11.0 \pm 0.3$ \\
\hline
\end{tabular}

Values presented as the mean \pm standard deviation. Total anthocyanins: cyanidin-3-Oglucoside $(\mathrm{C} 3 \mathrm{Gl})$, cyanidin-3-O-rutinoside (C3R), peonidin-3-O-glucoside (Peo3Gl) and peonidin-3-O-rutinoside (Peo3R). citric acid, as can be clearly observed in the contour plot in Figure 2. The ethanol and citric acid contribute to increase the overall yield, which is a consequence of the ethanol polarity and the acid medium that increases the extraction of a higher quantity of components from the matrix and reduces the selectivity of the process. For example, the highest yield obtained was the result of a process that used pure ethanol and $0.3 \%$ of citric acid ( $\mathrm{pH} 3.7$ ).

In this study, the temperature did not significantly affect the anthocyanin extraction process from açai pulp by PLE. This result disagrees with the observations of Machado et al. (2014) in an anthocyanin extraction process from blackberry residues, where the temperature had a positive effect on the overall yield. The anthocyanins identified in the blackberry extracts showed higher yields when the PLE process was

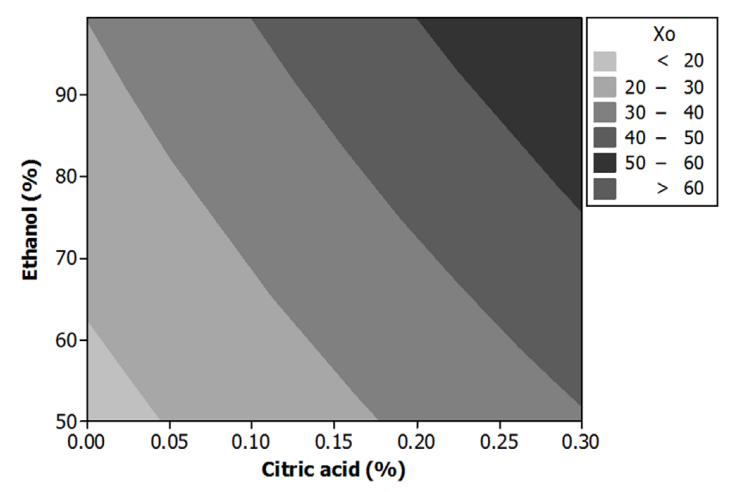

Figure 2. Contour plot of ethanol (\%) and citric acid (\%) for the overall extraction yield $\left(\mathrm{X}_{0}\right)$.

Table 2. Results obtained from the PLE process for açai extracts.

\begin{tabular}{|c|c|c|c|c|c|c|c|c|c|c|c|}
\hline \multirow[b]{2}{*}{ \# } & \multicolumn{4}{|c|}{ Conditions of PLE process } & \multicolumn{7}{|c|}{ Response variables } \\
\hline & $\begin{array}{c}\text { Temperature } \\
\left({ }^{\circ} \mathrm{C}\right)\end{array}$ & $\begin{array}{c}\text { Pressure } \\
\text { (bar) }\end{array}$ & $\begin{array}{c}\text { Ethanol } \\
(\%)\end{array}$ & $\begin{array}{c}\text { Citric acid } \\
(\%)\end{array}$ & $\begin{array}{c}\mathrm{X}_{0} \\
(\%)\end{array}$ & $\begin{array}{l}\text { C3Gl }^{*} \\
\left(\times 10^{-1}\right)\end{array}$ & $\mathrm{C}_{3} \mathrm{R}^{\star}$ & $\begin{array}{c}\text { Peo3Gl }^{*} \\
\left(\times 10^{-1}\right)\end{array}$ & $\begin{array}{l}\text { Peo3R }^{*} \\
\left(\times 10^{-1}\right)\end{array}$ & $\mathbf{T A}^{*}$ & $\begin{array}{l}\mathrm{AY} \\
(\%)\end{array}$ \\
\hline 1 & 30 & 20 & 50 & 0 & $16 \pm 1$ & $7 \pm 2$ & $6 \pm 1$ & $2.0 \pm 0.3$ & $3.0 \pm 0.8$ & $7 \pm 1$ & $10 \pm 1$ \\
\hline 2 & 60 & 20 & 50 & 0 & $15 \pm 2$ & $6 \pm 1$ & $5 \pm 1$ & $2.0 \pm 0.1$ & $3.0 \pm 0.4$ & $6 \pm 1$ & $8.0 \pm 0.5$ \\
\hline 3 & 30 & 80 & 50 & 0 & $18 \pm 3$ & $7 \pm 1$ & $5.0 \pm 0.9$ & $2.0 \pm 0.1$ & $3.0 \pm 0.5$ & $6 \pm 1$ & $11 \pm 2$ \\
\hline 4 & 60 & 80 & 50 & 0 & $17 \pm 3$ & $7.0 \pm 0.8$ & $5.0 \pm 0.9$ & $2.0 \pm 0.3$ & $3.0 \pm 0.7$ & $6 \pm 1$ & $10 \pm 0.1$ \\
\hline 5 & 30 & 20 & 99.5 & 0 & $30 \pm 5$ & $3.0 \pm 0.6$ & $2.0 \pm 0.4$ & $0.8 \pm 0.2$ & $1.0 \pm 0.4$ & $2.0 \pm 0.6$ & $6.0 \pm 0.4$ \\
\hline 6 & 60 & 20 & 99.5 & 0 & $36 \pm 7$ & $3.0 \pm 0.9$ & $2.0 \pm 0.5$ & $0.8 \pm 0.1$ & $1.0 \pm 0.3$ & $3.0 \pm 0.6$ & $9.0 \pm 0.4$ \\
\hline 7 & 30 & 80 & 99.5 & 0 & $31 \pm 3$ & $3.0 \pm 0.2$ & $2.0 \pm 0.2$ & $0.8 \pm 0.1$ & $2.0 \pm 0.2$ & $3.0 \pm 0.2$ & $8.0 \pm 0.1$ \\
\hline 8 & 60 & 80 & 99.5 & 0 & $24.0 \pm 0.2$ & $4.0 \pm 0.4$ & $2.0 \pm 0.3$ & $1.0 \pm 0.1$ & $2.0 \pm 0.2$ & $3.0 \pm 0.4$ & $7.0 \pm 0.7$ \\
\hline 9 & 30 & 20 & 50 & 0.3 & $34 \pm 1$ & $2.0 \pm 0.3$ & $1.0 \pm 0.2$ & $0.6 \pm 0.1$ & $1.0 \pm 0.1$ & $2.0 \pm 0.3$ & $6.0 \pm 0.6$ \\
\hline 10 & 60 & 20 & 50 & 0.3 & $41 \pm 1$ & $2.0 \pm 0.5$ & $2.0 \pm 0.4$ & $0.6 \pm 0.1$ & $1.0 \pm 0.1$ & $2.0 \pm 0.4$ & $9 \pm 1$ \\
\hline 11 & 30 & 80 & 50 & 0.3 & $42 \pm 5$ & $2.0 \pm 0.5$ & $1.0 \pm 0.3$ & $0.5 \pm 0.1$ & $1.0 \pm 0.1$ & $2.0 \pm 0.3$ & $7 \pm 1$ \\
\hline 12 & 60 & 80 & 50 & 0.3 & $40 \pm 5$ & $2.0 \pm 0.2$ & $2.0 \pm 0.2$ & $0.6 \pm 0.1$ & $1.0 \pm 0.1$ & $2.0 \pm 0.2$ & $7.0 \pm 0.1$ \\
\hline 13 & 30 & 20 & 99.5 & 0.3 & $58 \pm 2$ & $0.7 \pm 0.1$ & $0.3 \pm 0.1$ & $0.3 \pm 0.1$ & $0.7 \pm 0.1$ & $0.5 \pm 0.1$ & $3.0 \pm 0.6$ \\
\hline 14 & 60 & 20 & 99.5 & 0.3 & $61 \pm 8$ & $0.8 \pm 0.2$ & $0.4 \pm 0.1$ & $0.3 \pm 0.1$ & $0.7 \pm 0.2$ & $0.6 \pm 0.1$ & $3.0 \pm 0.9$ \\
\hline 15 & 30 & 80 & 99.5 & 0.3 & $58 \pm 3$ & $0.7 \pm 0.1$ & $0.4 \pm 0.1$ & $0.3 \pm 0.1$ & $0.7 \pm 0.1$ & $0.5 \pm 0.1$ & $3.0 \pm 0.8$ \\
\hline 16 & 60 & 80 & 99.5 & 0.3 & $64 \pm 9$ & $0.8 \pm 0.1$ & $0.4 \pm 0.1$ & $0.3 \pm 0.1$ & $0.7 \pm 0.1$ & $0.5 \pm 0.1$ & $3.0 \pm 0.2$ \\
\hline
\end{tabular}

${ }^{*}$ Expressed as $\mathrm{mg} / \mathrm{g}$ extract, d.b.; $\mathrm{X}_{0}$ overall extraction yield (\%, d.b.), TA the amount of total anthocyanins in the extract and AY the extraction yield anthocyanin (\%, d.b.) from the PLE process. Values presented as the mean \pm standard deviation. Total anthocyanins: cyanidin-3-O-glucoside (C3Gl), cyanidin-3-O-rutinoside (C3R), peonidin-3-O-glucoside (Peo3Gl) and peonidin-3-O-rutinoside (Peo3R). 
performed using acidified water ( $\mathrm{pH}$ 2.5) and temperatures between 60 and $80^{\circ} \mathrm{C}$ at $75 \mathrm{bar}$. Although some PLE processes commonly use high temperatures to obtain higher yields, in this work, moderate temperatures were considered in order to maintain the integrity of the anthocyanins. According to Liu et al. (2014), phenolic compound such as anthocyanins are thermolabile, and therefore, the use of high temperatures should be avoid to prevent the degradation of the compounds.

\section{Anthocyanin composition in the PLE extracts}

In this study, to determine the composition of the extracts, two major anthocyanins (C3Gl and C3R) were selected. C3Gl is known as one of the most predominant anthocyanins in nature and in the açai fruit (Del Pozo-Insfran et al., 2004), and C3R has been reported to be one of the most thermally stable anthocyanins (Rubinskiene et al., 2005; Sui et al., 2014). As shown in Table 1, the anthocyanin C3R represents the highest content in the total composition of anthocyanins in the frozen açai pulp. This behavior is uncommon in açai fresh pulp and blackberry (Rubus fruticosus L.) residues, according to values reported by Del Pozo-Insfran et al. (2004) and Machado et al. (2014), respectively, where the anthocyanin $\mathrm{C} 3 \mathrm{Gl}$ is the predominant compound in the extracts. This difference can be explained due to process conditions through which the raw material used in this work was obtained, and the water content in the raw material (Welch et al., 2008; Yamaguchi et al., 2015).

Yamaguchi et al. (2015) highlighted the presence of C3Gl and C3R in the açai extracts. Both compounds contribute biological properties to the extracts such as antioxidant, anti-inflammatory, anti-proliferative and cardio-protective activities. The presence of these anthocyanins (C3Gl and C3R) in the frozen açai pulp extracts, as shown in Table 1, indicates the potential antioxidant potential activity of the extracts obtained by the PLE process, as presented in Table 2. Conversely, two other anthocyanins with minor concentrations were identified: Pe3Gl and Pe3R.

The total anthocyanin (TA) content is given as a function of the process parameters in Table 2. It should also be noted that over the temperature and pressure ranges studied, TA was not significantly affected by any of these factors. Instead, once again, the TA was significantly affected by the combination of solvent and citric acid effects $\left(p_{\text {value }}<0.01\right)$.

Vieira et al. (2013) evaluated the influence of ultrasonic and agitated bed extraction methods on the anthocyanin composition of extracts obtained from jussara (Euterpe edulis) pulp. For the above study, the anthocyanin contents were significantly affected by the extraction time, ethanol concentrations in acidified water and S/F ratios, but not by the extraction temperature or differences between the extraction methods studied.

Contrary to the behavior shown by the overall yield, the TA composition presented a constant increment inversely proportional to the increment in concentration of ethanol and citric acid as observed in Figure 3. The highest amount of TA was obtained when ethanol/water $(50: 50 \mathrm{v} / \mathrm{v})$ was used as a solvent (pH 6.1), which demonstrates the solubility of anthocyanins in aqueous solutions (Pina et al., 2012). Although small quantities of citric acid can improve the extraction efficiency if the color stability of the anthocyanins is increased under acid conditions (Adjé et al., 2010), in this work, the addition of citric acid did not show a positive effect on the quantity of anthocyanins extracted. Conversely, the effects of the solvent and citric acid on $\mathrm{X}_{0}$ and TA in PLE extracts were different. Due to the higher quantities of ethanol and citric acid that increase the extraction of other components from raw material, the TA in the extract is also reduced.

\section{Anthocyanin yield (AY)}

The anthocyanin yield is given as a function of temperature, pressure, solvent and citric acid in Table 2 . The yield varied from $2.7 \%$ d.b. to $10.6 \%$ d.b. The anthocyanin yield was significantly affected by the combination of solvent and citric acid $\left(p_{\text {value }}=0.01\right)$. It is important to highlight that in the range of temperature and pressure tested, neither of the two parameters significantly affected the extraction process. The interaction between ethanol and citric acid appears to be the key factor in the extraction process. In Figure 4 is the contour plot of the interaction of ethanol and citric acid. Greater anthocyanin yields were obtained when the solvent had a greater proportion of water and in the absence of citric acid. As was established previously, a lower ethanol content contributes to the extraction process. In the same way, the process had a better performance when lower quantities of citric acid were used. As established previously,

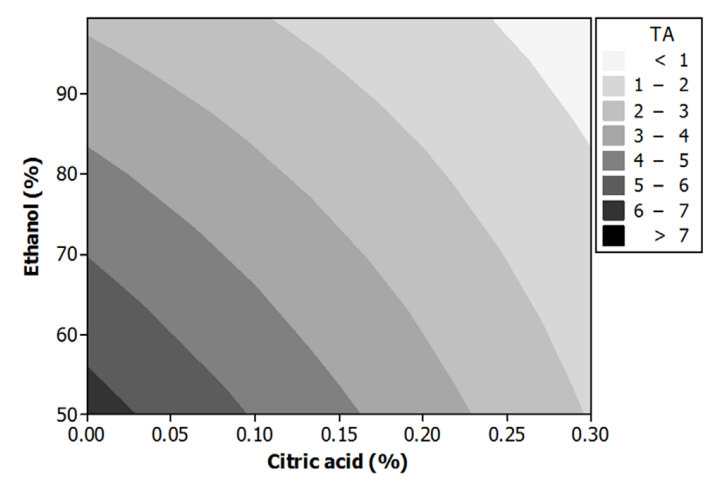

Figure 3. Contour plot of ethanol (\%) and citric acid (\%) for the total anthocyanins (TA) in the extract.

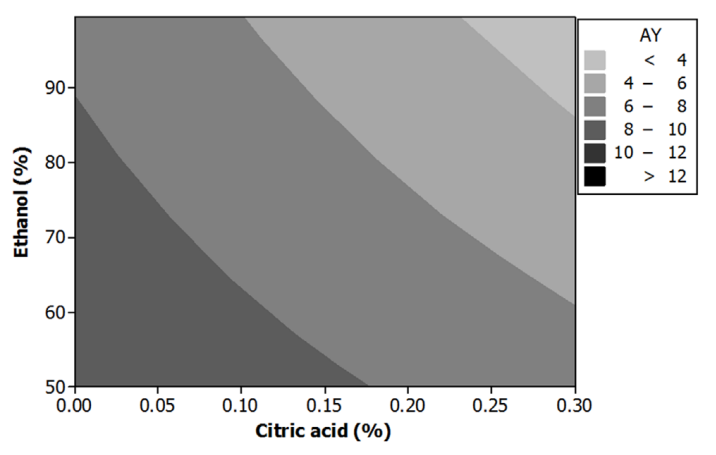

Figure 4. Contour plot of ethanol (\%) and citric acid (\%) for the extraction yield of anthocyanin (AY). 
a lower ethanol content contributed to the extraction process because the solubility of the anthocyanins is increased in aqueous solutions. In the same way, the process had a better performance when lower quantities of citric acid were used. The citric acid in this study increases the release of other compounds, which has the counter-effect of lowering the purity of the extract and decreasing in the anthocyanin yield.

However, the use of citric acid in other research has been successful. For example, Adjé et al. (2010) studied the ultrasound-assisted extraction of anthocyanins from the flowers of Delonix regia using water as an extraction solvent. In that work, the researchers extracted the anthocyanins using acidified water (sulfuric acid $(0.01 \mathrm{~N})$ and citric acid $(0.01 \mathrm{~N}))$. The results obtained showed better results when the process was performed using a higher concentration of citric acid. Although the use of citric acid seems have a better protective effect on anthocyanins than other acids, such as sulfuric acid, the use of citric acid in anthocyanin extraction is a topic that still being discussed. For example, citric acid does not have a positive effect in all anthocyanin extraction research. According to Pacheco-Palencia et al. (2007), the presence of citric acid in anthocyanin-rich systems can promote the degradation of compounds with a negative effect on the color retention. Therefore, further research regarding the use of citric acid during anthocyanin extraction should be conducted to clarify the effects of the citric acid in the extraction process. Conversely, after performing the statistical analysis, and due to the AY values obtained in this work, subsequent studies on increasing the proportion of water in the extraction solvent are recommended.

In this study, the temperature and pressure did not have a positive or negative effect on the extraction process; therefore, it is possible to establish that the use of the PLE process in anthocyanin extraction is not recommended, at least in the evaluated range of temperature and pressure. However, the results obtained in this work are relevant because they contribute to the purpose of obtaining anthocyanin-rich extracts from frozen açai fruit pulp. A similar behavior was observed by Rodrigues et al. (2014). The authors recommended, instead of the PLE process, the use of a low-pressure solvent extraction (LPSE) technique to obtain better results.

\section{Conclusions}

The results of this study show that anthocyanin-rich extracts can be obtained from frozen açai pulp in an environmentally friendly process such as the PLE process. The results indicate that the anthocyanin extraction was affected primarily by the extraction solvent and the acid citric percentage. The temperature and pressure did not significantly affect the extraction process. Specifically, increasing the water proportion in the extraction solvent improved the extraction efficiency of the anthocyanin, while increasing the citric acid negatively affected the extraction process. The best results for the anthocyanin extraction were ethanol/water $(50: 50 \mathrm{v} / \mathrm{v})$ without citric acid to acidulate the extraction solvent. The application of the PLE process to the recovery of anthocyanin biocompounds from frozen açai pulp was not determined conclusively, as in the evaluated range of temperature and pressure, neither of the two parameters had a significant effect on the anthocyanin extraction. Although this study proved that anthocyanins from frozen açai pulp are present in a fully functional form in the extracts obtained, further research is necessary to understand the effects of the process conditions. Another range of temperature and pressure, a minor concentration of citric acid and larger quantities of water in the extraction solvent could be evaluated to optimize the process.

\section{References}

Adjé, F., Lozano, Y. F., Lozano, P., Adima, A., Chemat, F., \& Gaydou, E. M. (2010). Optimization of anthocyanin, flavonol and phenolic acid extractions from Delonix regia tree flowers using ultrasound-assisted water extraction. Industrial Crops and Products, 32(3), 439-444. http://dx.doi.org/10.1016/j.indcrop.2010.06.011.

Altunkaya, A., \& Gökmen, V. (2009). Effect of various anti-browning agents on phenolic compounds profile of fresh lettuce (L. sativa). Food Chemistry, 117(1), 122-126. http://dx.doi.org/10.1016/j. foodchem.2009.03.085.

Brasil. Ministério da Agricultura, Pecuária e do Abastecimento. (2000, January 10). Regulamento técnico geral para fixação dos padrões de identidade e qualidade para polpa de fruta (Instrução normativa ${ }^{\circ}$ 01, de 7 de janeiro de 2000). Diário Oficial [da] República Federativa do Brasil. Retrieved from http://www.engetecno.com.br/port/ legislacao/doces_polpa_frutas.htm.

Carabias-Martínez, R., Rodríguez-Gonzalo, E., Revilla-Ruiz, P., \& Hernández-Méndez, J. (2005). Pressurized liquid extraction in the analysis of food and biological samples. Journal of Chromatography A, 1089(1-2), 1-17. PMid:16130765. http://dx.doi.org/10.1016/j. chroma.2005.06.072.

Del Pozo-Insfran, D., Brenes, C. H., \& Talcott, S. T. (2004). Phytochemical composition and pigment stability of Açai (Euterpe oleracea Mart.). Journal of Agricultural and Food Chemistry, 52(6), 1539-1545. PMid:15030208. http://dx.doi.org/10.1021/jf035189n.

Kang, J., Xie, C., Li, Z., Nagarajan, S., Schauss, A. G., Wu, T., \& Wu, X. (2011). Flavonoids from acai (Euterpe oleracea Mart.) pulp and their antioxidant and anti-inflammatory activities. Food Chemistry, 128(1), 152-157. PMid:25214342. http://dx.doi.org/10.1016/j. foodchem.2011.03.011.

Kruger, M. J., Davies, N., Myburgh, K. H., \& Lecour, S. (2014). Proanthocyanidins, anthocyanins and cardiovascular diseases. Food Research International, 59, 41-52. http://dx.doi.org/10.1016/j. foodres.2014.01.046.

Liazid, A., Barbero, G. F., Azaroual, L., Palma, M., \& Barroso, C. G. (2014). Stability of anthocyanins from red grape skins under pressurized liquid extraction and ultrasound-assisted extraction conditions. Molecules (Basel, Switzerland), 19(12), 21034-21043. PMid:25517342. http://dx.doi.org/10.3390/molecules191221034.

Liu, J., Sandahl, M., Sjöberg, P. J. R., \& Turner, C. (2014). Pressurised hot water extraction in continuous flow mode for thermolabile compounds: extraction of polyphenols in red onions. Analytical and Bioanalytical Chemistry, 406(2), 441-445. PMid:24091739. http:// dx.doi.org/10.1007/s00216-013-7370-7.

Machado, A. P. D. F., Pasquel-Reátegui, J. L., Barbero, G. F., \& Martínez, J. (2014). Pressurized liquid extraction of bioactive compounds from blackberry (Rubus fruticosus L.) residues: a comparison with conventional methods. Food Research International, 77(Pt 3), 675-683.

Mane, S., Bremner, D. H., Tziboula-Clarke, A., \& Lemos, M. A. (2015). Effect of ultrasound on the extraction of total anthocyanins from Purple Majesty potato. Ultrasonics Sonochemistry, 27, 509-514. PMid:26186873. http://dx.doi.org/10.1016/j.ultsonch.2015.06.021. 
Newsome, A. G., Culver, C. A., \& Van Breemen, R. B. (2014). Nature's palette: the search for natural blue colorants. Journal of Agricultural and Food Chemistry, 62(28), 6498-6511. PMid:24930897. http:// dx.doi.org/10.1021/jf501419q.

Nieto, A., Borrull, F., Pocurull, E., \& Marcé, R. M. (2010). Pressurized liquid extraction: a useful technique to extract pharmaceuticals and personal-care products from sewage sludge. Trends in Analytical Chemistry, 29(7), 752-764. http://dx.doi.org/10.1016/j.trac.2010.03.014.

Oliveira, E. N. A. d., \& Santos, D. C. (2011). Processamento e avaliação da qualidade de licor de açaí (Euterpe oleracea Mart.). Revista do Instituto Adolfo Lutz, 70, 534-541.

Pacheco-Palencia, L. A., Hawken, P., \& Talcott, S. T. (2007). Juice matrix composition and ascorbic acid fortification effects on the phytochemical, antioxidant and pigment stability of açai (Euterpe oleracea Mart.). Food Chemistry, 105(1), 28-35. http://dx.doi. org/10.1016/j.foodchem.2007.03.027.

Pina, F., Melo, M. J., Laia, C. A. T., Parola, A. J., \& Lima, J. C. (2012). Chemistry and applications of flavylium compounds: a handful of colours. Chemical Society Reviews, 41(2), 869-908. PMid:21842035. http://dx.doi.org/10.1039/C1CS15126F.

Richter, B. E., Jones, B. A., Ezzell, J. L., Porter, N. L., Avdalovic, N., \& Pohl, C. (1996). Accelerated solvent extraction: a technique for sample preparation. Analytical Chemistry, 68(6), 1033-1039. http:// dx.doi.org/10.1021/ac9508199.

Rodrigues, L. M., Alcázar-Alay, S. C., Petenate, A. J., \& Meireles, M. A. A. (2014). Bixin extraction from defatted annatto seeds. Comptes Rendus. Chimie, 17(3), 268-283. http://dx.doi.org/10.1016/j.crci.2013.10.010.

Rodrigues, S., Fernandes, F. A. N., Brito, E. S., Sousa, A. D., \& Narain, N. (2015). Ultrasound extraction of phenolics and anthocyanins from jabuticaba peel. Industrial Crops and Products, 69, 400-407. http://dx.doi.org/10.1016/j.indcrop.2015.02.059.

Rubinskiene, M., Jasutiene, I., Venskutonis, P. R., \& Viskelis, P. (2005). HPLC determination of the composition and stability of blackcurrant anthocyanins. Journal of Chromatographic Science, 43(9), 478-482. PMid:16212794. http://dx.doi.org/10.1093/chromsci/43.9.478.
Schauss, A. G., Wu, X., Prior, R. L., Ou, B., Huang, D., Owens, J., Agarwal, A., Jensen, G. S., Hart, A. N., \& Shanbrom, E. (2006a). Antioxidant capacity and other bioactivities of the freeze-dried Amazonian palm berry, Euterpe oleraceae Mart. (Acai). Journal of Agricultural and Food Chemistry, 54(22), 8604-8610. PMid:17061840. http://dx.doi. org/10.1021/jf0609779.

Schauss, A. G., Wu, X., Prior, R. L., Ou, B., Patel, D., Huang, D., \& Kababick, J. P. (2006b). Phytochemical and nutrient composition of the freeze-dried amazonian palm berry, Euterpe oleraceae Mart. (Acai). Journal of Agricultural and Food Chemistry, 54(22), 85988603. PMid:17061839. http://dx.doi.org/10.1021/jf060976g.

Spada, P. D. S., Dani, C., Bortolini, G. V., Funchal, C., Henriques, J. A. P., \& Salvador, M. (2009). Frozen fruit pulp of Euterpe oleraceae mart. (Acai) prevents hydrogen peroxide-induced damage in the cerebral cortex, cerebellum, and hippocampus of rats. Journal of Medicinal Food, 12(5), 1084-1088. PMid:19857073. http://dx.doi. org/10.1089/jmf.2008.0236.

Sui, X., Dong, X., \& Zhou, W. (2014). Combined effect of pH and high temperature on the stability and antioxidant capacity of two anthocyanins in aqueous solution. Food Chemistry, 163, 163-170. PMid:24912712. http://dx.doi.org/10.1016/j.foodchem.2014.04.075.

Vieira, G. S., Cavalcanti, R. N., Meireles, M. A. A., \& Hubinger, M. D. (2013). Chemical and economic evaluation of natural antioxidant extracts obtained by ultrasound-assisted and agitated bed extraction from jussara pulp (Euterpe edulis). Journal of Food Engineering, 119(2), 196-204. http://dx.doi.org/10.1016/j.jfoodeng.2013.05.030.

Welch, C. R., Wu, Q., \& Simon, J. E. (2008). Recent advances in anthocyanin analysis and characterization. Current Analytical Chemistry, 4(2), 75-101. PMid:19946465. http://dx.doi.org/10.217 4/157341108784587795.

Yamaguchi, K. K. L., Pereira, L. F. R., Lamarão, C. V., Lima, E. S., \& Veiga-Junior, V. F. (2015). Amazon acai: Chemistry and biological activities: a review. Food Chemistry, 179, 137-151. PMid:25722148. http://dx.doi.org/10.1016/j.foodchem.2015.01.055. 